\title{
Exigência nutricional de proteína bruta para codornas japonesas (Coturnix coturnix japonica) na fase de postura
}

\author{
[Nutritional requirement of crude protein for japanese quail \\ (Coturnix coturnix japonica) in the production phase] \\ R.C. Lima ${ }^{1}$, F.G.P. Costa ${ }^{2}$, C.C. Goulart ${ }^{3}$, L.E. Cavalcante ${ }^{2}$, E.R. Freitas ${ }^{4}$, J.H.V. Silva ${ }^{2}$, \\ L.S. Dantas ${ }^{2}$, V.P. Rodrigues ${ }^{1}$ \\ ${ }^{1}$ Aluna de pós-graduação - Universidade Federal da Paraíba - UFPB - Areia, PB \\ ${ }^{2}$ Universidade Federal da Paraíba - UFPB - Areia, PB \\ 3universidade Federal Vale do Acaraú - UVA - Sobral, CE \\ ${ }^{4}$ Universidade Federal do Ceará - UFC - Fortaleza, CE
}

\begin{abstract}
RESUMO
O objetivo do trabalho foi determinar o melhor nível de proteína bruta na alimentação de codornas japonesas em fase de produção. Foram utilizadas 300 codornas com 16 semanas de idade, alojadas em gaiolas, em um delineamento inteiramente casualizado, com cinco tratamentos, seis repetições e dez aves por unidade experimental. Os níveis avaliados foram 14, 17, 20, 23 e 26\% de proteína bruta, e as dietas foram formuladas para serem isoenergéticas. Foi verificado efeito quadrático para consumo de ração, peso de ovo, massa de ovo, ingestão de energia, eficiência energética por dúzia de ovo, coeficiente de digestibilidade de nitrogênio, retenção de nitrogênio, peso de gema, casca e albúmen. Efeito linear foi verificado para produção de ovos, ingestão de proteína, conversão alimentar por massa de ovos, eficiência energética por massa de ovo em $\mathrm{kg}$, peso final e gravidade específica. Não houve efeito significativo para conversão alimentar por dúzia e concentração sérica de ácido úrico. Recomenda-se nível de $20 \%$ de proteína bruta para codornas japonesas em fase de postura.
\end{abstract}

Palavras-chave: ácido úrico, digestibilidade, gema, ovo, retenção de nitrogênio

\begin{abstract}
The aim of this study was to determine the best level of crude protein in the diet of Japanese quails in the production phase. A total of 300 quails at 16 weeks of age in cages, in a completely randomized design with five treatments and six replicates of ten birds per experimental unit was used. The levels evaluated were 14, 17, 20, 23 and 26\% crude protein and diets were formulated to be isoenergetic. A quadratic effect was observed for feed intake, egg weight, egg mass, energy intake, energy efficiency per dozen eggs, nitrogen digestibility, shell percentage, nitrogen retention, weight of yolk, albumen and shell. A linear effect was observed for egg production, protein intake, feed conversion by egg mass, energy efficiency per egg mass in $\mathrm{kg}$, final weight and yolk percentage and specific gravity. There was no significant effect on feed conversion per dozen, percentage of albumen, shell thickness and serum uric acid. The recommendation is of a $20 \%$ crude protein level for Japanese quail during the laying phase.
\end{abstract}

Keywords: uric acid digestibility, egg yolk, egg, nitrogen retention

\section{INTRODUÇÃO}

Durante muito tempo, as exigências nutricionais de codornas japonesas foram supridas fazendo-se uso de tabelas de exigências nutricionais de outros países, como o NRC (1994), não sendo essas ideais para as condições tropicais brasileiras (Pizzolante et al., 2006), além do que a maioria dos dados compilados nessa publicação foi obtida há mais de vinte e quatro anos com aves que apresentavam potencial genético

Recebido em 1 de fevereiro de 2013

Aceito em 16 de dezembro de 2013

E-mail: raffazoo@yahoo.com.br 
bastante diferente das codornas criadas atualmente.

Dentre os nutrientes importantes para o desempenho e produção de ovos, podemos destacar a proteína bruta (PB), tendo em vista que as exigências variam de acordo com a taxa de crescimento e produção de ovos. Quando fornecida em níveis marginais, a proteína bruta promove redução no crescimento e produção de ovos, por conta do desvio de parte desta para funções menos vitais, prejudicando assim o desenvolvimento corporal e a produção. Já o seu excesso pode limitar o desempenho das aves, pois o catabolismo aminoacídico requer gasto extra de energia para excreção de nitrogênio na forma de ácido úrico (Jordão Filho et al., 2006).

Verificou-se, entretanto, que as aves não apresentam uma exigência específica para proteína bruta, mas para aminoácidos essenciais e não essenciais, sendo estes últimos sintetizados a partir de nitrogênio não específico. Assim, os níveis de proteína bruta devem ser suficientes para que a poedeira possa garantir um satisfatório "pool" de nitrogênio para a síntese de aminoácidos não essenciais, assegurando também a presença de aminoácidos essenciais através da utilização de aminoácidos industriais. Vale ressaltar a importância de níveis de proteína e aminoácidos na dieta de poedeiras, tendo em vista que o requerimento de proteína está associado com a taxa de produção e tamanho dos ovos.

Dessa forma, o objetivo do trabalho foi determinar o nível de proteína bruta sobre o desempenho e qualidade de ovos de codornas na fase de produção.

\section{MATERIAL E MÉTODOS}

O experimento foi realizado nas dependências do Setor de Avicultura do Departamento de Zootecnia da Universidade Federal da Paraíba, no período de 10/05/2010 a 23/08/2010. Foram utilizadas 300 codornas japonesas com 16 semanas de idade, com peso médio inicial de $189,61 \pm 6,34 \mathrm{~g}$. As aves foram alojadas em gaiolas de postura $(33 \times 33 \times 33 \mathrm{~cm})$, em um delineamento experimental inteiramente ao acaso, com cinco tratamentos e seis repetições de 10 aves, durante cinco períodos de 21 dias.

Para a escolha dos níveis de proteína bruta a serem utilizados nas rações experimentais, utilizou-se na ração intermediária o nível 20\%, recomendado por Silva e Costa (2009), e os demais níveis variando em três pontos percentuais para mais e para menos. Sendo assim, os níveis estudados foram 14, 17, 20, 23 e $26 \%$ de proteína bruta.

As dietas (Tab. 1) foram formuladas para serem isoenergéticas, seguindo a recomendação para energia metabolizável (EM) de Silva e Costa (2009), de $2.800 \mathrm{kcal}$ de EM/kg de ração, com base em aminoácidos digestíveis e suplementadas com os aminoácidos industriais DL-metionina, L-lisina HCL e L-isoleucina, podendo atender ou exceder as recomendações dos aminoácidos essenciais. Os dados de composição de alimentos foram baseados segundo Rostagno et al. (2005).

Os parâmetros avaliados foram consumo de ração (g/ave/dia), percentagem de postura (\%), peso de ovo (g), massa de ovo (g/ave/dia), conversão alimentar ( $\mathrm{kg}$ de ração/kg de massa e $\mathrm{kg}$ de ração/dúzia de ovo), ingestão de proteína (g/ave/dia) e energia (kcal/ave/dia), eficiência energética (kcal de EM/dúzia de ovo e kcal de $\mathrm{EM} / \mathrm{massa}$ de ovo em $\mathrm{kg}$ ), peso (g) de gema, casca e albúmen, gravidade específica (GE, $\left.\mathrm{g} / \mathrm{cm}^{3}\right)$, peso final $(\mathrm{g})$, retenção de nitrogênio (g/ave/dia), concentração sérica de ácido úrico $(\mathrm{mg} / \mathrm{dL})$ e coeficiente de digestibilidade de nitrogênio (CDN, \%).

O consumo de ração foi obtido através da pesagem do fornecimento, no início, e da sobra, ao final de cada período experimental. A produção de ovos foi registrada diariamente pela manhã, e no final de cada período foram calculadas as percentagens de postura. A massa de ovo (g/ave/dia) foi calculada multiplicando-se o número de ovos produzidos pelo peso médio dos ovos $(\mathrm{g})$. 
Tabela 1. Ingredientes e composição nutricional calculada para codornas japonesas em fase de produção

\begin{tabular}{|c|c|c|c|c|c|}
\hline & \multicolumn{5}{|c|}{ Níveis de proteína bruta (\%) } \\
\hline & 14,00 & 17,00 & 20,00 & 23,00 & 26,00 \\
\hline \multicolumn{6}{|l|}{ Ingredientes } \\
\hline Milho & 70,001 & 65,108 & 56,783 & 46,012 & 50,576 \\
\hline Soja $45 \%$ & 15,302 & 23,736 & 32,849 & 41,943 & 35,634 \\
\hline Óleo de soja & 0,000 & 0,000 & 1,167 & 3,163 & 5,004 \\
\hline Calcário & 7,107 & 7,097 & 7,081 & 7,059 & 7,039 \\
\hline Fosfato bicálcico & 1,062 & 1,001 & 0,948 & 0,906 & 0,867 \\
\hline Sal comum & 0,521 & 0,519 & 0,521 & 0,525 & 0,527 \\
\hline DL-metionina & 0,307 & 0,227 & 0,150 & 0,082 & 0,043 \\
\hline L-isoleucina & 0,394 & 0,245 & 0,092 & 0,000 & 0,000 \\
\hline L-lisina HCL & 0,643 & 0,378 & 0,099 & 0,000 & 0,000 \\
\hline Cloreto de colina & 0,100 & 0,100 & 0,100 & 0,100 & 0,100 \\
\hline Vitamina $^{1}$ & 0,100 & 0,100 & 0,100 & 0,100 & 0,100 \\
\hline Mineral $^{2}$ & 0,100 & 0,100 & 0,100 & 0,100 & 0,100 \\
\hline Antioxidante ${ }^{3}$ & 0,010 & 0,010 & 0,010 & 0,010 & 0,010 \\
\hline Inerte $^{4}$ & 4,354 & 1,379 & 0,000 & 0,000 & 0,000 \\
\hline Total & 100 & 100 & 100 & 100 & 100 \\
\hline \multicolumn{6}{|l|}{ Composição Nutricional Calculada } \\
\hline Proteína bruta $(\%)$ & 14,00 & 17,00 & 20,00 & 23,00 & 26,00 \\
\hline Energia Metabolizável (kcal/kg) & 2.800 & 2.800 & 2.800 & 2.800 & 2.800 \\
\hline Cálcio $(\%)$ & 3,050 & 3,050 & 3,050 & 3,050 & 3,050 \\
\hline Cloro $(\%)$ & 0,393 & 0,394 & 0,395 & 0,397 & 0,398 \\
\hline Potássio (\%) & 0,492 & 0,632 & 0,775 & 0,909 & 1,037 \\
\hline Sódio $(\%)$ & 0,230 & 0,230 & 0,230 & 0,230 & 0,230 \\
\hline Fósforo disponível (\%) & 0,280 & 0,280 & 0,280 & 0,280 & 0,280 \\
\hline Arginina dig. (\%) & 0,742 & 0,995 & 1,256 & 1,508 & 1,747 \\
\hline Isoleucina dig. (\%) & 0,870 & 0,870 & 0,870 & 0,870 & 0,870 \\
\hline Lisina dig. $(\%)$ & 1,030 & 1,030 & 1,030 & 1,162 & 1,362 \\
\hline Leucina dig. (\%) & 1,169 & 1,392 & 1,604 & 1,792 & 1,968 \\
\hline Met.+cist.dig. (\%) & 0,700 & 0,700 & 0,700 & 0,700 & 0,700 \\
\hline Metionina dig. (\%) & 0,498 & 0,461 & 0,425 & 0,395 & 0,390 \\
\hline Treonina dig. (\%) & 0,432 & 0,551 & 0,671 & 0,785 & 0,892 \\
\hline Triptofano dig. (\%) & 0,122 & 0,167 & 0,214 & 0,259 & 0,302 \\
\hline Valina dig. (\%) & 0,538 & 0,684 & 0,831 & 0,969 & 1,099 \\
\hline
\end{tabular}

${ }^{1}$ Suplemento vitamínico: vit. A: 7.000.000 UI; vit. D3: 2.100.000 UI; vit. E: 50.000mg; vit. K3: 2.000mg; vit. B1: 2.000mg; vit. B2: 4.000mg; vit. B6: 3.000mg; vit. B12: 3.000mg; Niacina: 39.800mg; Ácido Pantotênico: $15.620 \mathrm{mg}$; Folato: $1.000 \mathrm{mg}$; Selênio: 200mg; Biotina: 100mg; Antioxidante: $100.000 \mathrm{mg}$ e Veículo-1.000g.; ${ }^{2}$ Suplemento mineral: Mn: 75.000mg; Zn: 70.000mg; Fe: 50.000mg; Cu: 8.500mg; I: 1500mg; Co: 200mg; Veículo: 1.000g.; ${ }^{3}$ Etoxiquin; ${ }^{4}$ Areia lavada.

A conversão alimentar por massa ( $\mathrm{kg}$ de ração $/ \mathrm{kg}$ de massa) foi determinada através da relação entre a ração consumida e a massa de ovo produzida dentro do período. A conversão alimentar por dúzia (kg de ração/dúzia de ovo) foi calculada pela relação entre o consumo de ração e a quantidade de dúzias produzidas no período. O peso final das codornas foi obtido ao final do experimento, com a pesagem de todas as codornas da parcela experimental para obtenção do peso médio.
A ingestão de proteína e energia foi calculada em função da quantidade de proteína bruta e energia metabolizável consumida por grama de ração ingerida, respectivamente. A eficiência energética por dúzia (kcal de EM/dúzia de ovo) foi determinada através da relação entre a quantidade de energia consumida e as dúzias de ovos produzidas, e a eficiência energética por massa de ovo (kcal de EM/massa de ovo em kg) foi determinada através da relação entre a quantidade de energia consumida e a massa de ovos produzida. 
A GE foi determinada pelo método de flutuação salina, conforme metodologia descrita por Hamilton (1982). Mais dois ovos foram utilizados para as demais avaliações de qualidade interna.

Para avaliar os efeitos dos níveis de proteína bruta na ração sobre a retenção de nitrogênio e determinação do coeficiente de digestibilidade de nitrogênio, iniciou-se a coleta total de excretas, que foi realizada duas vezes ao dia, às $8 \mathrm{~h}$ e $16 \mathrm{~h}$, durante os quatro últimos dias do quinto período experimental, de acordo com Matterson et al. (1965). Em seguida, as amostras foram analisadas em laboratório, segundo metodologia descrita por Silva e Queiroz (2002).

A excreção de ácido úrico foi utilizada como indicador da qualidade da proteína ingerida pelas aves. Foram colhidos $2 \mathrm{~mL}$ de sangue de cada ave no final do experimento. $\mathrm{O}$ soro obtido após a centrifugação do sangue foi armazenado em freezer a $-20^{\circ} \mathrm{C}$ e posteriormente analisada a concentração sérica de ácido úrico, através de kit comercial (Labtest) e leitura em espectrofotômetro, de acordo com as instruções do fabricante.

Os dados foram analisados utilizando o SAS (Statistical..., 2003). Determinaram-se as estimativas das exigências pelo modelo de regressão polinomial. No modelo quadrático, as exigências de proteína bruta foram obtidas por derivação das equações e corresponderam ao nível que maximizou a variável dependente.

\section{RESULTADOS E DISCUSSÃO}

Durante o período experimental, a média das temperaturas máxima e mínima foram $25,63^{\circ} \mathrm{C}$ e $18,9^{\circ} \mathrm{C}$, respectivamente, e umidade relativa de $85 \%$. Foi observado efeito quadrático para consumo de ração, peso do ovo, massa de ovo, ingestão de energia e eficiência energética (kcal/dúzia) com melhores resultados aos níveis 19,$72 ; 21,65 ; 21,85 ; 19,56$; e 19,30\% de proteína bruta, respectivamente. A retenção de nitrogênio e o coeficiente de digestibilidade de nitrogênio apresentaram menores valores nos níveis $17,84 \mathrm{e}$ $19,84 \%$ de PB, respectivamente. Efeito linear crescente foi verificado para produção de ovos, ingestão de proteína e peso final, e linear decrescente para conversão alimentar por massa de ovo e eficiência energética $(\mathrm{kcal} / \mathrm{kg})$. Não houve efeito significativo para conversão alimentar por dúzia de ovos e concentração sérica de ácido úrico.

O consumo de ração (Tab. 2) apresentou efeito quadrático, aumentando até o nível 19,72\% de $\mathrm{PB}$ e, a partir desse nível, seguindo com uma diminuição. Efeito semelhante foi verificado por Pinto et al. (2002), com aumento do consumo até o nível $21,80 \%$ de proteína bruta.

Tabela 2. Valores médios das variáveis de desempenho de codornas japonesas em fase de produção em função dos diferentes níveis de proteína bruta

\begin{tabular}{|c|c|c|c|c|c|c|}
\hline \multirow[b]{2}{*}{ Variáveis } & \multicolumn{5}{|c|}{ Proteína bruta $(\%)$} & \multirow[b]{2}{*}{$\mathrm{CV}(\%)$} \\
\hline & 14,00 & 17,00 & 20,00 & 23,00 & 26,00 & \\
\hline Consumo de ração (g/ave/dia) ${ }^{2 * *}$ & 25,99 & 27,78 & 28,88 & 26,62 & 25,92 & 5,64 \\
\hline Produção de ovos $(\%)^{1 *}$ & 88,56 & 91,54 & 92,28 & 93,66 & 92,50 & 3,37 \\
\hline Peso do ovo $(\mathrm{g})^{2 * *}$ & 10,49 & 11,66 & 12,21 & 11,90 & 11,58 & 2,76 \\
\hline Massa de ovo (g/ave/dia) ${ }^{2 * *}$ & 9,25 & 10,52 & 11,22 & 11,10 & 10,68 & 4,72 \\
\hline Ingestão de proteína (g/ave/dia) ${ }^{1 *}$ & 3,64 & 4,72 & 5,78 & 6,12 & 6,74 & 5.61 \\
\hline Ingestão de energia (kcal/ave/dia) $2 * *$ & 72,78 & 77,77 & 78,00 & 74,54 & 72,58 & 5,51 \\
\hline Conversão alimentar $(\mathrm{kg} / \mathrm{massa})^{1 * *}$ & 2,82 & 2,67 & 2,58 & 2,40 & 2,43 & 6,70 \\
\hline Conversão alimentar $(\mathrm{kg} / \mathrm{dz})^{3}$ & 0,355 & 0,372 & 0,373 & 0,343 & 0,340 & 6,89 \\
\hline Eficiência energética $(\mathrm{kcal} / \mathrm{dz})^{2 * *}$ & 964 & 1.030 & 1.047 & 980 & 940 & 4,87 \\
\hline Eficiência energética $(\mathrm{kcal} / \mathrm{kg})^{1 * *}$ & 7.897 & 7.633 & 7.128 & 6.391 & 6.525 & 5,40 \\
\hline Peso final $(\mathrm{g})^{1 * *}$ & 171,00 & 178,77 & 182,21 & 183,21 & 186,27 & 3,97 \\
\hline
\end{tabular}

${ }^{1}$ Efeito linear; ${ }^{2}$ Efeito quadrático; ${ }^{3} \mathrm{Não}$ significativo; $*(\mathrm{P}<0,05) ; * *(\mathrm{P}<0,01)$

Baker (1993) afirmou que pode ocorrer aumento no consumo alimentar em rações com baixo nível de proteína bruta; entretanto, se o nível proteico for exageradamente alto ou baixo, a ave terá melhor consumo em um nível intermediário (Swenson, 1996). De acordo com Moura et al. (2010), se o conteúdo proteico da ração é baixo, as aves podem vir a aumentar o seu consumo 
alimentar para compensar parcialmente o menor conteúdo em aminoácidos. Contudo, para Veloso et al. (2012), não há efeito da proteína bruta sobre o consumo de ração porque a ação da proteína não é resultado apenas da quantidade fornecida na ração, mas também de sua qualidade, ou seja, da concentração e do balanceamento dos aminoácidos.

A ingestão diária de proteína aumentou linearmente com o aumento dos níveis de proteína bruta da ração. Observa-se que, para cada aumento de $1 \%$ na proteína da ração, houve aumento médio de $0,25 \mathrm{~g}$ na ingestão proteica. Verifica-se, portanto, que, apesar de o consumo de ração ter diminuído a partir de 19,72\% de PB, as aves permaneceram aumentando a ingestão proteica; fato que pode ser explicado possivelmente por conta da maior concentração de proteína presente por grama de ração ingerida.

O nível de $26 \%$ de proteína bruta promoveu a maior ingestão de proteína $(6,74 \mathrm{~g} / \mathrm{ave} / \mathrm{dia})$, valor próximo ao recomendado por Pinto et al. (2002), que sugeriram que codornas em produção devem ingerir, em média, 6,02g de proteína diariamente. Já Freitas et al. (2005) e Moura et al. (2010) verificaram consumo diário de 4,4 e 4,8g, respectivamente. As diferenças nos resultados obtidos na literatura podem ser atribuídas a variações das condições experimentais, como produção de ovos, peso da ave, balanço de aminoácidos, condições de alojamento, dentre outros.
A ingestão de energia aumentou até o nível de $19,56 \%$ de proteína bruta, diminuindo em seguida, possivelmente acompanhando a diminuição do consumo de ração que ocorreu a partir de $19,72 \%$ de PB. Pelo fato de as rações terem sido formuladas como isoenergéticas, a redução do consumo de ração fez com que houvesse uma menor ingestão de energia por grama de ração consumida. Apesar de as aves normalmente apresentarem uma capacidade de regular a ingestão de energia através do controle do consumo de ração, esse mecanismo regulatório pode ser ineficiente em alguns casos (Oliveira et al., 2002; Mendonça et al., 2008). Diversos fatores podem interferir nas exigências de proteína e energia e, dentre eles, Oliveira et al. (2002) citam a genética, peso, idade, condições de alojamento da ave, balanço e disponibilidade de aminoácidos na dieta.

Para o peso de ovo, observou-se efeito quadrático (Tab. 3) com máximo peso aos $21,65 \%$ de PB. Valores semelhantes foram apresentados por Freitas et al. (2005), que verificaram aumento do peso do ovo até o nível de 21,16\%. De acordo com Murakami (2002), o tamanho do ovo é altamente dependente da ingestão diária de proteína pelo fato de as aves poedeiras terem pouca habilidade em estocá-la. Dessa forma, o aumento da ingestão de proteína promoveu máximo aumento no peso dos ovos, em nível bem próximo ao recomendado por Silva e Costa (2009), que é de $20 \%$ de PB.

Tabela 3. Equações de regressão e coeficientes de determinação das variáveis de desempenho, coeficiente de digestibilidade de nitrogênio e retenção de nitrogênio de codornas japonesas em fase de produção em função dos diferentes níveis de proteína bruta

\begin{tabular}{lcc}
\hline Variáveis & Regressão & $\mathrm{R}^{2}$ \\
\hline Produção de ovos (\%) & $\mathrm{Y}=85,03+0,333 \mathrm{x}$ & 0,68 \\
Consumo de ração (g/ave/dia) & $\mathrm{Y}=2,629+2,603 \mathrm{x}-0,066 \mathrm{x}^{2}$ & 0,79 \\
Massa de ovo (g/ave/dia) & $\mathrm{Y}=-4,419+1,442 \mathrm{x}-0,033 \mathrm{x}^{2}$ & 0,99 \\
Peso do ovo (g) & $\mathrm{Y}=-1,688+1,299 \mathrm{x}-0,030 \mathrm{x}^{2}$ & 0,96 \\
Conversão alimentar/massa & $\mathrm{Y}=3,273-0,034 \mathrm{x}$ & 0,91 \\
Eficiência energética (Kcal/kg) & $\mathrm{Y}=9773,8-132,94 \mathrm{x}$ & 0,90 \\
Eficiência energética (kcal/dz) & $\mathrm{Y}=159,8+90,781 \mathrm{x}-2,3523 \mathrm{x}^{2}$ & 0,89 \\
Ingestão de proteína (g/ave/dia) & $\mathrm{Y}=0,3323+0,2534 \mathrm{x}$ & 0,96 \\
Ingestão de energia (kcal/ave/dia) & $\mathrm{Y}=24,205+5,4655 \mathrm{x}-0,1397 \mathrm{x}^{2}$ & 0,84 \\
Peso final (g) & $\mathrm{Y}=156,97+1,1659 \mathrm{x}$ & 0,89 \\
Retenção de nitrogênio (g/ave/dia) & $\mathrm{Y}=0,935-0,0678 \mathrm{x}+0,0019 \mathrm{x}^{2}$ & 0,73 \\
CDN (\%) & $\mathrm{Y}=181,5-14,29 \mathrm{x}+0,360 \mathrm{x}^{2}$ & 0,91 \\
\hline
\end{tabular}

$\mathrm{CDN}$ - coeficiente de digestibilidade de nitrogênio 
Ao mesmo tempo em que o peso do ovo atingiu sua máxima resposta, verificou-se paralelamente uma redução no consumo de ração a partir de $19,72 \%$ de $\mathrm{PB}$, fato esse que provavelmente promoveu consumo insuficiente de nutrientes para a manutenção do bom peso dos ovos. Apesar de ter havido um aumento linear da ingestão de proteína, esta não foi suficiente para manter constante o peso dos ovos, tendo em vista que, além de proteína (aminoácidos), os ovos são compostos por outros nutrientes, como lipídeos, carboidratos, minerais e vitaminas. Por conta disso, houve uma redução no tamanho do ovo a partir de $21,65 \%$.

A produção de ovos aumentou linearmente com o aumento dos níveis de proteína da ração. Cada $1 \%$ de aumento da proteína bruta da ração promoveu $0,33 \%$ de aumento da produção de ovos. Pinto et al. (2002) verificaram efeito quadrático, ao passo que Freitas et al. (2005) não verificaram efeito significativo com o aumento dos níveis proteicos da ração na produção de ovos de codornas japonesas. Outros pesquisadores (Vohra e Roudybush, 1971; Begin e Insko Jr., 1972; Sakurai, 1981) também observaram aumento significativo na produção de ovos com o aumento do nível de proteína da ração.

De acordo com Murakami (2002), a taxa de postura possui correlação positiva com o teor proteico da ração e, portanto, o aumento linear observado na ingestão de proteína pode ter contribuído para o comportamento semelhante observado na produção de ovos. Porém, segundo Leeson et al. (1996), a energia é o fator de maior importância para que sejam obtidos ótimos índices de postura.

No presente trabalho, a ingestão de energia apresentou efeito quadrático com o aumento dos níveis de proteína e, mesmo nessas condições, a produção de ovos manteve-se crescente. Sendo assim, é possível inferir que o aumento do consumo de proteína ocasionado pelos maiores níveis de PB da ração foi suficiente para promover o aumento da produção de ovos, mesmo com a redução da ingestão de energia a partir de $19,56 \%$ de $\mathrm{PB}$.

Para massa de ovo, foi observado efeito quadrático, com máximo valor em $21,85 \%$ de PB. Efeito semelhante foi apresentado por Pinto et al. (2002), com maior valor em $23,45 \%$ de PB.
Considerando que a massa de ovo é uma variável calculada através do peso médio e do número de ovos produzidos, o resultado obtido no presente trabalho está dentro do esperado por ter sido influenciado pelo peso dos ovos. Para Johri e Vohra (1977) e Ribeiro et al. (2003), o aumento da proteína bruta na ração promove aumento na massa produzida, já que o peso e a massa de ovo são influenciados pela ingestão diária de proteína em poedeiras (Murakami e Furlan, 2002).

A conversão alimentar por massa de ovo melhorou linearmente com o aumento dos níveis de proteína bruta da ração. Resultados semelhantes foram obtidos por Freitas et al. (2005). O resultado do presente estudo está associado ao comportamento das equações de regressão observado para o consumo de ração e massa de ovo, em que ambos apresentaram efeito quadrático. Dessa forma, a relação numérica estabelecida entre as duas variáveis determinou o efeito linear verificado para a conversão alimentar (kg/massa).

Observou-se que, para cada $1 \%$ a mais de proteína bruta na ração, as codornas apresentaram redução de 0,034 pontos na conversão alimentar. No presente estudo, entre o menor (14\%) e o maior (26\%) nível estudado de proteína bruta, houve uma variação de 0,07g/ave/dia no consumo de ração e, para a massa de ovo produzida, a diferença foi de $1,43 \mathrm{~g} / \mathrm{ave} / \mathrm{dia}$. Verifica-se que a diferença entre os consumos de ração foi consideravelmente inferior à diferença entre as massas de ovo produzidas, que, mesmo diminuindo a partir de $21,85 \%$ de PB na ração, foi sempre superior ao consumo de ração, fazendo, assim, com que a conversão alimentar melhorasse ao longo dos níveis estudados.

Verificou-se que a eficiência energética para produção de uma dúzia de ovos apresentou efeito quadrático com máximo valor em 19,30\% de PB, ao passo que a eficiência para produção de $1 \mathrm{~kg}$ de massa de ovo melhorou linearmente com o aumento dos níveis de proteína da ração. Já para a eficiência energética para produção de dúzia de ovos, o ponto de máxima resposta desta ficou próximo dos apresentados pelo consumo de ração $(19,72 \%)$ e ingestão de energia $(19,56 \%)$.

Observa-se que, com o aumento inicial da ingestão de energia, as codornas disponibilizaram mais EM para produção de uma 
dúzia de ovos; com o menor consumo de ração e a consequente redução da ingestão energética (a partir de 19,56\%), houve uma melhora na eficiência energética (kcal/dz) e as aves conseguiram manter crescente a produção de ovos, embora o peso do ovo tenha sido reduzido.

De acordo com Barreto et al. (2007), a energia no metabolismo animal sofre partição, de modo que somente pequena parte $(20$ a $27 \%)$ do total de energia consumida é destinada à produção. Isso indica que o baixo aporte energético na ração, muitas vezes, não é suficiente para atender à manutenção e à produção das aves e, portanto, uma deficiência energética pode vir a prejudicar o desempenho produtivo destas. Contudo, no presente estudo, foi possível manter a produção de ovos em níveis crescentes, mesmo com um menor aporte energético.

O peso final das codornas aumentou linearmente sob o efeito dos níveis de proteína da ração. Para cada aumento de $1 \%$ na proteína bruta da ração, houve aumento de $1,16 \mathrm{~g}$ no peso final da codorna. Esse resultado assemelha-se com os apresentados por Pinto et al. (2002) e Freitas et al. (2005), que também verificaram que as codornas aumentavam seu peso em função do aumento dos níveis de proteína. De acordo com Freitas et al. (2005), durante o ciclo de postura, as aves necessitam de proteína para manutenção, crescimento corporal e aumento da massa de ovos produzida.

Além da proteína como nutriente essencial para manutenção e crescimento corporal, o componente nutricional energia metabolizável também pode ter influenciado na variação de peso corporal observada, pois, segundo Freitas et al. (2005), a ingestão de energia é uma variável que influencia o ganho de peso. Assim, considerando que, com o aumento dos níveis de proteína da ração, as aves não mantiveram constante a ingestão de energia, é possível que essa variação tenha promovido aumento do peso final, uma vez que essa variável depende da ingestão de energia para ser alterada.

Para a qualidade dos ovos (Tab. 4), foi verificado efeito quadrático para peso de gema, de albúmen e de casca, com máximo valor com 23,22; 21,13; e $22,46 \%$, respectivamente. Para gravidade específica foi verificado efeito linear crescente.

Tabela 4. Valores médios das variáveis de qualidade de ovos de codornas japonesas em fase de produção em função dos diferentes níveis de proteína bruta

\begin{tabular}{lcccccc}
\hline Variáveis & \multicolumn{7}{c}{ Proteína bruta $(\%)$} \\
\cline { 2 - 6 } & 14,00 & 17,00 & 20,00 & 23,00 & 26,00 & CV $(\%)$ \\
\hline Albúmen $(\%)^{3}$ & 53,65 & 54,30 & 54,73 & 53,83 & 53,36 & 2,14 \\
Gema $(\mathrm{g})^{2 * *}$ & 3,40 & 3,70 & 3,94 & 3,92 & 3,92 & 5,19 \\
Casca $(\mathrm{g})^{2 * *}$ & 0,842 & 0,893 & 0,927 & 0,921 & 0,916 & 2,85 \\
Albúmen $(\mathrm{g})^{2 * *}$ & 5,40 & 5,93 & 6,22 & 6,02 & 5,84 & 4,23 \\
Gravidade específica $\left(\mathrm{g} / \mathrm{cm}^{3}\right)^{1 *}$ & 1,0710 & 1,0710 & 1,0712 & 1,0715 & 1,0715 & 0,07 \\
\hline
\end{tabular}

1Efeito linear; ${ }^{2}$ Efeito quadrático; ${ }^{3}$ Não significativo; $*(\mathrm{P}<0,05) ; * *(\mathrm{P}<0,01)$; CV - coeficiente de variação.

Observou-se efeito dos níveis de proteína bruta sobre o peso de gema, albúmen e casca, fato que contribuiu para o efeito quadrático observado para o peso do ovo (Tab. 5). A redução no peso dos constituintes do ovo pode estar associada à redução no consumo de ração que, como consequência, reduziu o consumo de nutrientes e de energia necessários à formação do ovo. Observa-se que essa redução do peso dos constituintes do ovo ocorreu em níveis muito próximos de $\mathrm{PB}$ e todos com comportamento quadrático, semelhante ao do consumo de ração e da ingestão de energia.

Tabela 5. Equações de regressão e coeficientes de determinação das variáveis de qualidade de ovos de codornas japonesas em fase de produção, em função dos diferentes níveis de proteína bruta

\begin{tabular}{lcc}
\hline Variáveis & Regressão & $\mathrm{R}^{2}$ \\
\hline Gema $(\mathrm{g})$ & $\mathrm{Y}=0,3701+0,3112 \mathrm{x}-0,0067 \mathrm{x}^{2}$ & 0,98 \\
Casca $(\mathrm{g})$ & $\mathrm{Y}=0,324+0,0539 \mathrm{x}-0,0012 \mathrm{x}^{2}$ & 0,98 \\
Albúmen $(\mathrm{g})$ & $\mathrm{Y}=-0,5509+0,638 \mathrm{x}-0,0151 \mathrm{x}^{2}$ & 0,95 \\
Gravidade específica $\left(\mathrm{g} / \mathrm{cm}^{3}\right)$ & $\mathrm{Y}=1,0703+0,00005 \mathrm{x}$ & 0,93 \\
\hline
\end{tabular}


A gravidade específica aumentou linearmente com os níveis de proteína bruta, em que, para cada $1 \%$ de aumento da proteína, verificou-se aumento de $5 \times 10^{-5} \mathrm{~g} / \mathrm{cm}^{3}$ na gravidade específica. Freitas et al. (2004) relataram que a gravidade específica dos ovos apresenta relação direta com o percentual de casca, podendo ser utilizado como método indireto na determinação da qualidade desta.
O teor de ácido úrico (Tab. 6) no plasma sanguíneo não foi influenciado significativamente pelos níveis de proteína bruta, variando no presente estudo de 1,61 a 2,44mg/dL. Esses dados encontram-se dentro dos valores normais para aves poedeiras, que, segundo Schmidt et al. (2007), para aves em postura, estão entre 2 a $7 \mathrm{mg} / \mathrm{mL}$.

Tabela 6. Valores médios da concentração sérica de ácido úrico, retenção de nitrogênio e coeficiente de digestibilidade de nitrogênio de codornas japonesas em fase de produção, em função dos diferentes níveis de proteína bruta

\begin{tabular}{lcccccc}
\hline & \multicolumn{7}{c}{ Proteína bruta $(\%)$} & \\
\cline { 2 - 6 } Variáveis & 14,00 & 17,00 & 20,00 & 23,00 & 26,00 & CV (\%) \\
\hline Concentração sérica de ácido úrico & 1,62 & 2,09 & 1,61 & 2,44 & 2,14 & 36,47 \\
(mg/dL) & 0,339 & 0,347 & 0,341 & 0,324 & 0,456 & 9,53 \\
Retenção de N (g/ave/dia) ${ }^{1 * *}$ & 50,95 & 45,19 & 40,00 & 41,25 & 55,00 & 6,18 \\
CDN (\%) & $1 * *$ & & &
\end{tabular}

${ }^{1}$ Efeito quadrático; ${ }^{2} \mathrm{Não}$ significativo; **(P<0,01); $\mathrm{CDN}$ - Coeficiente de digestibilidade de nitrogênio; $\mathrm{CV}$ coeficiente de variação.

De acordo com Bell (1971), os valores de ácido úrico para aves estão relacionados ao metabolismo renal e hepático e são a principal forma de excreção de bases nitrogenadas. A excreção de ácido úrico é utilizada como indicador da qualidade da proteína ingerida pelas aves, pois menos proteína é depositada no músculo e mais ácido úrico é excretado quando as aves recebem na alimentação proteína de baixa qualidade, ou quando são sujeitas ao desequilíbrio de aminoácidos.

A retenção de nitrogênio (Tab. 3) diminuiu até o nível $17,84 \%$ de PB e depois aumentou novamente. Observa-se, assim, que o aumento dos níveis de proteína fez com que houvesse maior ingestão de proteína e que esta pôde ser aproveitada pela ave através de sua menor excreção e, consequentemente, maior retenção.

O coeficiente de digestibilidade de nitrogênio apresentou redução até o nível 19,84\% de proteína bruta e depois aumentou, corroborando os resultados obtidos para retenção de nitrogênio.

\section{CONCLUSÕES}

Os resultados sinalizam que se pode recomendar o nível de $22 \%$ de proteína bruta para codornas japonesas em fase de postura.

\section{REFERÊNCIAS}

BAKER, D.H. Amino acid nutrition of pigs and poutry. In: COLE, D.J.A.; HARESING, W.; GARNWORTH, P.C. 2.ed. Recent developments in pig nutrition. Lough barangh: Nottingam University, 1993. p.60-75.

BARRETO, S.L.T.; QUIRINO, B.J.S.; BRITO, C.O.; UMIGI, R.T. et al. Níveis de energia metabolizável para codornas japonesas na fase inicial de postura. Rev. Bras. Zootec., v.36, p.79-85, 2007.

BEGIN, J.J.; INSKO JR., W.M. The effects os dietary protein level on the reproductive performance of Coturnix breeder hens. Poultry Sci., v.51, p.16621669, 1972.

BELL, D.J. Non-protein and is fractions in plasma and erythrocytes. In: BELL, D.J.; FREEMAN, B.M. (Ed). Physiology and biochemistry of the domestic fowl. London: Academic Press, v.2, p.921-931, 1971.

FREITAS, A.C.; FUENTES, M.F.F.; FREITAS, E.R.; SUCUPIRA, F.S. et al. Efeito de níveis de proteína bruta e de energia metabolizável na dieta sobre o desempenho de codornas de postura. Rev. Bras. Zootec., v.34, p.838-846, 2005.

FREITAS, E.R.; SAKOMURA, N.K.; GONZALEZ, M.M. et al. Comparação de métodos de determinação da gravidade específica de ovos de poedeiras comerciais. Pesq. Agropec. Bras., v.39, p.509-512, 2004.

HAMILTON, R.M.G. Methods and factors that affect the measurement of egg shell quality. Poultry Sci., v.61, p.2022-2039, 1982. 
JOHRI, T.S.; VOHRA, P. Protein requirements of Coturnix coturnix japonica for reproduction using purified diets. Poultry Sci., v.56, p.350-353, 1977.

JORDÃO FILHO, J.; SILVA, J.H.V.; SILVA, E.L. et al. Exigência de lisina para poedeiras semipesadas durante o pico de postura. Rev. Bras. Zootec., v.35, (supl.), p.1728-1734, 2006.

LEESON, S.; CASTON, L.; SUMMER, J.D. et al. Broiler response to energy or energy and protein dilution in the finisher diet. Poultry Sci., v.75, p.522528, 1996.

MATTERSON, L.D.; POTTER, L.M.; STUTZ, N.W. et al. The metabolizable energy of feed ingredients for chickens. Agricult. Experim. Stat. Rese. Report, v.7, p.3-11, 1965.

MENDONÇA, M.O.; SAKOMURA, N.K.; SANTOS, F.R. et al. Níveis de energia metabolizável para machos de corte de crescimento lento criados em semiconfinamento. Rev. Bras. Zootec., v.37, p.14331440,2008

MOURA, G.S.; BARRETO, S.L.T.; LANNA, E.A.T. Efeito da redução da densidade energética de dietas sobre as características do ovo de codorna japonesa. Rev. Bras. Zootec., v.39, p.1266-1271, 2010.

MURAKAMI, A.E.; FURLAN, A.C. Pesquisa na nutrição e alimentação de codornas em postura no Brasil. In: SIMPÓSIO INTERNACIONAL DE COTURNICULTURA, 2002, Lavras. Anais... Lavras: [s.n] 2002. p.113-120.

MURAKAMI, A.E. Nutrição e alimentação de codornas japonesas em postura. In: REUNIÃO ANUAL DA SOCIEDADE BRASILEIRA DE ZOOTECNIA, 39., 2002, Recife. Anais... Recife: Sociedade Brasileira de Zootecnia, 2002, p.283-309.

NATIONAL research council - NRC. Committee on Animal Nutrition. 9.ed. Washington: National Academy of Science - NAS, 1994. 155 p.

OLIVEIRA, N.T.E.; SILVA, M.A.; SOARES, R.T.R.N.; FONSECA, J.B. et al. Exigências de proteína bruta e energia metabolizável para codornas japonesas criadas para a produção de carne. Rev. Bras. Zootec., v.31, p.675-686, 2002.

PINTO, R.; FERREIRA, A.S.; ALBINO, L.F.T.; GOMES, P.C. et al. Níveis de proteína e energia para codornas japonesas em postura. Rev. Bras. Zootec., v.31, p.1761-1770, 2002.
PIZZOLANTE, C.C.; SALDANHA, E.S.P.B.; GARCIA, E.A. et al. Níveis de sal comum em rações de codornas japonesas (Coturnix coturnix japonica) em final de produção. Cienc. Anim. Bras., v.7, p.123130, 2006.

RIBEIRO, M.L.G.; SILVA, J.H.V.; DANTAS, M.O. et al. Exigências nutricionais de lisina para codornas durante a fase de produção em função do nível de proteína da ração. Rev. Bras. Zootec., v.32, p.156-161, 2003.

ROSTAGNO, H.S.; ALBINO, L.F.T.; DONZELE, J.L. et al. Tabelas brasileiras para aves e suínos: composição de alimentos e exigências nutricionais. 2.ed. Viçosa: Universidade Federal de Viçosa, 2005. $186 \mathrm{p}$.

SAKURAI, H. Influence of dietary levels of protein and energy on nitrogen and energy balance for egg production of Japanese quail. Poultry Sci., v.18, p.185190, 1981.

SCHMIDT, E.; LOCATELLI-DITTRICH, R.; SANTIN, E.; PAULILLO, A. Patologia clínica em aves de produção - Uma ferramenta para monitorar a sanidade avícola-revisão. Arch. Vet. Sci., v.12, p.9-20, 2007.

SILVA, J.H.V.; COSTA, F.G.P. Tabelas para codornas japonesas e europeias. 2.ed. FUNEP: Jaboticabal, 110p, 2009.

SILVA, D.J.; QUEIROZ, A.C. Análise de alimentos: métodos químicos e biológicos. 3.ed. Viçosa, MG: Editora UFV, 2002. 165p.

STATISTICAL analisys sistem - SAS/STAT: User's guide, 2003.

SWENSON, M.J.; REECE, W.O. Dukes - Fisiologia dos animais domésticos. 11.ed. Rio de Janeiro: Guanabara Koogan S.A. 856p. 1996.

VELOSO R.C.; PIRES, A.V.; TIMPANI, V.D.T. et al. Níveis de proteína bruta e energia metabolizável em uma linhagem de codorna de corte. Maringá, v.34, p.169-174, 2012.

VOHRA, P.; ROUDYBUSH, T. The effect of various levels of dietary protein on growth and egg production of Coturnix coturnix japonica. World's Poultry Sci., v.50, p.1081-1084, 1971. 